\title{
Lipopolysaccharide-Induced Increase in Intestinal Epithelial Tight Permeability Is Mediated by Toll-Like Receptor 4/Myeloid Differentiation Primary Response 88 (MyD88) Activation of Myosin Light Chain Kinase Expression
}

\author{
Meghali Nighot, ${ }^{* \dagger}$ Rana Al-Sadi, ${ }^{*}$ Shuhong Guo, ${ }^{*}$ Manmeet Rawat, ${ }^{* \dagger}$ Prashant Nighot, ${ }^{*}$ Martin D. Watterson, ${ }^{\ddagger}$ and \\ Thomas Y. Ma*†
}

From the Department of Internal Medicine, * University of New Mexico School of Medicine, Albuquerque, New Mexico; the Albuquerque Veterans Affairs Medical Center, ${ }^{\dagger}$ Albuquerque, New Mexico; and the Drug Discovery Program, ${ }^{\ddagger}$ Northwestern University, Chicago, Illinois

\author{
Accepted for publication \\ August 22, 2017. \\ Address correspondence to \\ Thomas Y. Ma, M.D., Ph.D. \\ Department of Internal Medi- \\ cine, University of New Mexico \\ School of Medicine, mail stop \\ code 10 5550, Albuquerque, \\ NM 87131-0001. E-mail: \\ tma@salud.unm.edu.
}

\begin{abstract}
Lipopolysaccharides (LPSs) are a major component of the Gram-negative bacterial cell wall and play an important role in mediating intestinal inflammatory responses in inflammatory bowel disease. Although recent studies suggested that physiologically relevant concentrations of LPS (0 to $1 \mathrm{ng} / \mathrm{mL}$ ) cause an increase in intestinal epithelial tight junction (TJ) permeability, the mechanisms that mediate an LPSinduced increase in intestinal $\mathrm{TJ}$ permeability remain unclear. Herein, we show that myosin light chain kinase (MLCK) plays a central role in the LPS-induced increase in TJ permeability. Filter-grown Caco-2 intestinal epithelial monolayers and $\mathrm{C} 57 \mathrm{BL} / 6$ mice were used as an in vitro and in vivo intestinal epithelial model system, respectively. LPS caused a dose- and time-dependent increase in MLCK expression and kinase activity in Caco-2 monolayers. The pharmacologic MLCK inhibition and siRNA-induced knock-down of MLCK inhibited the LPS-induced increase in Caco-2 TJ permeability. The LPS increase in TJ permeability was mediated by toll-like receptor 4 (TLR-4)/MyD88 signal-transduction pathway up-regulation of MLCK expression. The LPS-induced increase in mouse intestinal permeability also required an increase in MLCK expression. The LPS-induced increase in intestinal permeability was inhibited in $\mathrm{MLCK}^{-/-}$and $\mathrm{TLR}_{-} 4^{-/-}$ mice. These data show, for the first time, that the LPS-induced increase in intestinal permeability was mediated by TLR-4/MyD88 signal-transduction pathway up-regulation of MLCK. Therapeutic targeting of these pathways can prevent an LPS-induced increase in intestinal permeability. (Am J Pathol 2017, 187: 2698-2710; https://doi.org/10.1016/j.ajpath.2017.08.005)
\end{abstract}

Lipopolysaccharide (LPS) plays an important pathogenic role in intestinal inflammation of Crohn disease and other inflammatory conditions. $^{1-4}$ It has been shown that circulating plasma LPS levels are elevated in intestinal permeability disorders, including Crohn disease and necrotizing enterocolitis, and play an integral role in inducing both intestinal tissue and systemic inflammatory responses. ${ }^{5-8}$ LPS binds to the Tolllike receptor 4 (TLR-4) located on the basolateral membranes of enterocytes and plasma membrane of circulating immune cells., ${ }^{2,9}$ The activation of TLR-4 receptor complex sets forth a diverse array of intracellular signaling pathways that determine the magnitude, type, and duration of the inflammatory response. ${ }^{10}$ Specifically, LPS has been shown to be an important pathogenic factor contributing to the intestinal inflammatory process in necrotizing enterocolitis and inflammatory bowel disease. ${ }^{11-14}$ LPS has also been shown to

Supported by a Veterans Affairs (VA) Research Service VA Merit Review grant (T.Y.M.) and National Institute of Diabetes and Digestive and Kidney Diseases grant RO 1-DK-64165-01 (T.Y.M.).

M.N., R.A.-S., and S.G. contributed equally to this work.

Disclosures: None declared. 
be an essential etiological factor mediating liver inflammation in alcoholic liver disease. ${ }^{15,16}$ In each of these diseases, defective intestinal tight junction (TJ) barrier has been shown to be a key etiological factor leading to endotoxemia and subsequent development of inflammatory response. ${ }^{15-17}$

It was shown earlier that the plasma concentration of LPS ranges from undetectable levels up to $0.2 \mathrm{ng} / \mathrm{mL} \cdot{ }^{18-20}$ On the other hand, patients with intestinal permeability disorders, such as Crohn disease, necrotizing enterocolitis, acute pancreatitis, alcoholic liver disease, and critical illnesses, have been shown to have elevated plasma LPS levels, ranging up to 2 to $10 \mathrm{ng} / \mathrm{mL}^{18-22}$ On the basis of these reports, LPS levels of 0 to $1.0 \mathrm{ng} / \mathrm{mL}$ are considered to be physiologically relevant; in contrast, LPS levels of 0 to $10 \mathrm{ng} /$ $\mathrm{mL}$ are considered to be clinically relevant. Most of the published studies used extreme pharmacologic concentrations of LPS, ranging between 50 and $1000 \mu \mathrm{g} / \mathrm{mL}$, which exceed the physiologically achievable concentrations by $10^{4}$ to $10^{7}$-fold, to assess various biological responses. ${ }^{23-27}$ At these extreme concentrations, LPS causes rapid cell death in various cell types studied, including intestinal and immune cells, ${ }^{24,25,27,28}$ and does not provide accurate depiction of biological activity of LPS as of the immune response in the cells and the activation of many downstream transcription factors. In contrast, we previously showed, for the first time, that LPS at physiologically achievable concentrations ( 0 to $1000 \mathrm{pg} / \mathrm{mL}$ ) and clinically achievable concentrations ( 0 to $10 \mathrm{ng} / \mathrm{mL}$ ) does not cause acute cell death. ${ }^{1,2}$ Moreover, LPS at concentrations up to $10 \mathrm{ng} / \mathrm{mL}$ did not affect intestinal TJ permeability up to 3 days of LPS exposure. LPS caused a selective increase in intestinal epithelial TJ permeability between days 3.5 and 4 that was associated with an increase in TLR-4 and CD14 basolateral membrane expression.

Myosin light chain kinase (MLCK) is a $\mathrm{Ca}^{2+} /$ calmodulinactivated enzyme that catalyzes the myosin light chain phosphorylation, triggering actin/myosin contraction and subsequent muscle contraction. ${ }^{29}$ MLCK exists in two isoforms: the short isoform (MLCK108) is ubiquitous in adult tissues, with smooth muscle cells containing the highest amounts; and the long isoform (MLCK210) is prominently expressed in embryonic smooth muscle cells and in adult cells of nonmuscular lineage, including enterocytes. ${ }^{30}$ The long isoform MLCK210 has been shown to play a crucial role in both physiological and pathologic regulation of intestinal TJ permeability. ${ }^{30-32}$ The overexpression of MLCK was sufficient to cause an increase in TJ permeability, ${ }^{33}$ and pharmacologic activation of MLCK produced an increase in epithelial TJ permeability. Previous studies have shown that a cytokine-induced increase in intestinal TJ permeability was also mediated by an increase in MLCK expression. ${ }^{34-36}$

As mentioned above, high pharmacologic doses of LPS cause rapid and diffuse epithelial cell death, leading to a rapid loss in intestinal epithelial barrier. ${ }^{37,38}$ In contrast, low physiological levels $(0.3$ to $1.0 \mathrm{ng} / \mathrm{mL}$ ) of LPS do not cause cell death, but cause a functional opening of the TJ barrier with an increase in TJ permeability. ${ }^{1,2}$ However, the specific intracellular mechanisms or the effector proteins responsible for the physiological or clinically achievable concentrations of LPS on intestinal TJ permeability remain unknown. The purpose of these studies was to determine the protein kinase and the intracellular processes responsible for the LPSinduced functional opening of the intestinal TJ barrier. Our results suggested that the TJ proteins, including zonula occludens protein 1 , claudins $1,2,3$, and 5 , and occludin, were not affected by LPS. Instead, the LPS-induced increase in intestinal TJ permeability mediated the TLR-4/Myd88 signaling pathway-regulated increase in MLCK transcript and protein expression and subsequent MLCK-induced opening of the TJ barrier.

\section{Materials and Methods}

\section{Reagents}

Dulbecco's modified Eagle's medium, trypsin, fetal bovine serum, glutamine, penicillin, streptomycin, phosphate-buffered saline (PBS), and horseradish peroxidase-conjugated secondary antibodies for Western blot analysis were purchased from Invitrogen Life Technologies (Carlsbad, CA). siRNA of MLCK, TLR-4, and transfection reagents were from Dharmacon (Lafayette, CO). LPS (O111:B4) and ML-7 were purchased from Sigma-Aldrich (St. Louis, MO). All other chemicals were of reagent grade and were purchased from Sigma-Aldrich, VWR (Aurora, CO), or Fisher Scientific (Pittsburgh, PA).

\section{Cell Culture}

Caco-2 cells (passage 20) were purchased from ATCC (Manassas, VA) and maintained at $37^{\circ} \mathrm{C}$ in a culture medium composed of Dulbecco's modified Eagle's medium with 4.5 $\mathrm{mg} / \mathrm{mL}$ glucose, $50 \mathrm{U} / \mathrm{mL}$ penicillin, $50 \mathrm{U} / \mathrm{mL}$ streptomycin, $4 \mathrm{mmol} / \mathrm{L}$ glutamine, $25 \mathrm{mmol} / \mathrm{L}$ HEPES, and $10 \%$ fetal bovine serum. The cells were kept at $37^{\circ} \mathrm{C}$ in a $5 \% \mathrm{CO}_{2}$ environment. Culture medium was changed every 2 days. The cells were subcultured by partial digestion with $0.25 \%$ trypsin and $0.9 \mathrm{mmol} / \mathrm{L}$ EDTA in $\mathrm{Ca}^{2+}$ - and $\mathrm{Mg}^{2+}$-free PBS. For growth on filters, high-density Caco-2 cells $\left(1 \times 10^{5}\right.$ cells) were plated on Transwell filters, with a $0.4-\mu \mathrm{m}$ pore (Corning Inc., Corning, NY), and monitored regularly by visualization with an inverted microscope (Eclipse TS100/ 100-F; Nikon, Melville, NY) and by epithelial resistance measurements. The human intestinal Caco-2 cell line has been extensively used over the past 20 years as an in vitro model system of functional epithelial barriers.

\section{Determination of Epithelial Monolayer Resistance and Paracellular Permeability}

The transepithelial electrical resistance of the filter-grown Caco-2 intestinal monolayers was measured using an epithelial voltmeter (EVOM; World Precision Instruments, 
Sarasota, FL), as previously reported. ${ }^{35,39}$ After treatment, including LPS (LPS was refreshed every 24 hours), ML-7, and siRNA, both apical and basolateral sides of the epithelium were bathed with Dulbecco's modified Eagle's medium. Electrical resistance was measured using 5\% difference on three consecutive measurements. The Caco-2 monolayer paracellular permeability was determined using inulin, an established paracellular marker. ${ }^{35,39,40}$ Unless specified otherwise, Dulbecco's modified Eagle's medium ( $\mathrm{pH}$ 7.4) was used as the incubation solution during the experiments. Buffered solution $(0.5 \mathrm{~mL})$ was added to the apical compartment, and $1.5 \mathrm{~mL}$ was added to the basolateral compartment to ensure equal hydrostatic pressure, as recommended by the manufacturer. Known concentrations of permeability marker inulin $(10 \mu \mathrm{mol} / \mathrm{L})$ and its radioactive tracer were added to the apical solution. Low concentrations of permeability marker were used to ensure that a negligible osmotic or concentration gradient was introduced. All flux studies were performed at $37^{\circ} \mathrm{C}$. For determination of mucosal-to-serosal flux rates of inulin, Caco-2-plated filters with an epithelial resistance of 400 to $550 \Omega \cdot \mathrm{cm}^{2}$ were used. All of the permeability experiments were repeated three to six times in triplicate.

\section{Assessment of Protein Expression by Western Blot Analysis}

To study the time-course effect of LPS on MLCK protein expression, Caco-2 monolayers were treated with LPS $(0.3 \mathrm{ng} / \mathrm{mL})$ from 1 to 5 days. At the end of the experimental period, Caco-2 monolayers were immediately rinsed with icecold PBS. Cells were lysed with lysis buffer: $50 \mathrm{mmol} / \mathrm{L}$ Tris- $\mathrm{HCl}(\mathrm{pH} \mathrm{7.5),} 150 \mathrm{mmol} / \mathrm{L} \mathrm{NaCl}, 500 \mu \mathrm{mol} / \mathrm{L} \mathrm{NaF}$, $2 \mathrm{mmol} / \mathrm{L}$ EDTA, $100 \mu \mathrm{mol} / \mathrm{L}$ vanadate, $100 \mu \mathrm{mol} / \mathrm{L}$ phenylmethylsulfonyl fluoride, $1 \mu \mathrm{g} / \mathrm{mL}$ leupeptin, $1 \mu \mathrm{g} / \mathrm{mL}$ pepstatin A, $40 \mathrm{mmol} / \mathrm{L}$ paranitrophenyl phosphate, $1 \mu \mathrm{g} / \mathrm{mL}$ aprotinin, and $1 \%$ Triton X-100. The cell lysates were placed in microfuge tubes and centrifuged at $10,000 \times g$ for 10 minutes in an Eppendorf centrifuge (5417R; Eppendorf, Hauppauge, NY) to obtain a clear lysate. The supernatant was collected, and protein concentration was determined using the Bio-Rad Protein Assay kit (Bio-Rad Laboratories, Hercules, CA). Laemmli gel loading buffer (catalog number 161-0737; Bio-Rad Laboratories) was added to the lysate containing 10 to $20 \mu \mathrm{g}$ of protein and boiled at $100^{\circ} \mathrm{C}$ for 7 minutes, after which proteins were separated on an SDS-PAGE gel. Proteins from the gel were transferred to the membrane (Trans-Blot Transfer Medium, Nitrocellulose Membrane; Bio-Rad Laboratories) overnight. The membrane was incubated for 2 hours in blocking solution ( $5 \%$ dry milk in tris-buffered saline-Tween 20 buffer). The membrane was then incubated with MLCK antibody (catalog number M7905; Sigma-Aldrich) in blocking solution. After a wash in tris-buffered saline-1\% Tween buffer, the membrane was incubated in horseradish peroxidase-goat anti-mouse IgG (catalog number ab-20043; Abcam, Cambridge, MA) and developed using the Santa
Cruz Western Blotting Luminol Reagents (Santa Cruz Biotechnology, Dallas, TX) on the Kodak BioMax MS film (Fisher Scientific, Pittsburgh, PA). The films were exposed between 5 seconds and 10 minutes.

\section{Enzyme-Linked Immunosorbent Assay-Based MLCK in Vitro Kinase Activity}

Biotinylated MLC was diluted in PBS and coated on streptavidin 96 -well plates at $37^{\circ} \mathrm{C}$ for 1 hour. The plates were washed three times with PBS, incubated with blocking solution $\left(1 \mathrm{mg} / \mathrm{mL}\right.$ bovine serum albumin in PBS) at $37^{\circ} \mathrm{C}$ for 1 hour, and then washed three times with PBS. The kinase reaction buffer $(90 \mu \mathrm{L})$, provided by the manufacturer (MBL International, Woburn, MA), and the treated samples $(10 \mu \mathrm{L})$ were added to the wells, and the kinase reaction was performed at $37^{\circ} \mathrm{C}$ for 30 to 60 minutes. The reaction was stopped by removing the reaction mixtures and washing the plates three times with buffer $(20 \mathrm{mmol} / \mathrm{L}$ Tris-HCl, $\mathrm{pH} 7.4$, $0.5 \mathrm{~mol} / \mathrm{L} \mathrm{NaCl}$, and $0.05 \%$ Tween 20 ). The washed plates were incubated with the anti-phosphorylated (phospho)MLC-S19 antibody (5 ng/mL; catalog number M6068; Sigma-Aldrich) at room temperature for 1 hour, after which the plates were washed four times with buffer. Horseradish peroxidase-goat anti-rabbit IgG (diluted at 1:2000 in washing buffer; catalog number ab-6721; Abcam) was added to the wells, and the plates were incubated at $37^{\circ} \mathrm{C}$ for 1 hour. The plates were washed four times and then incubated with $100 \mu \mathrm{L}$ substrate solution (tetramethylbenzidine) for 5 to 15 minutes at $37^{\circ} \mathrm{C}$. The reaction was stopped by adding $100 \mu \mathrm{L}$ of $0.5 \mathrm{~N}$ $\mathrm{H}_{2} \mathrm{SO}_{4}$. The absorbance at $450 \mathrm{~nm}$ was determined using the SpectraMax 190 (Molecular Devices, Sunnyvale, CA).

\section{siRNA Transfection}

Targeted siRNA of MLCK was obtained from Dharmacon. Caco-2 monolayers were transiently transfected using DharmaFect transfection reagent (Dharmacon). Briefly, cells $\left(5 \times 10^{5}\right.$ per filter) were seeded into a 12 -well transwell plate and grown to confluency. Caco-2 monolayers were then washed with PBS twice. Then, $0.5 \mathrm{~mL}$ Accell medium (Thermo Scientific, Lafayette, CO) was added to the apical compartment of each filter, and $1.5 \mathrm{~mL}$ was added to the basolateral compartment of each filter. MLCK siRNA or TLR-4 siRNA ( $5 \mathrm{ng})$ and DharmaFect reagent $(2 \mu \mathrm{L})$ were preincubated in Accell medium. After 5 minutes of incubation, the two solutions were mixed, and the mixture was added to the apical compartment of each filter. The LPS experiments were conducted 24 hours after transfection. The silencing was confirmed by Western blot analysis.

\section{RNA Isolation and Reverse Transcription}

Caco- 2 cells $\left(5 \times 10^{5}\right.$ cells per filter $)$ were seeded into 12 -well Transwell permeable inserts and grown to confluency. Filtergrown Caco- 2 cells were then treated with LPS from 1 to 5 
days. At the end of the experimental period, cells were washed with ice-cold PBS. Total Caco-2 RNA was isolated by using the RNeasy Kit (Qiagen, Valencia, CA), according to the manufacturer's protocol. Total RNA concentration was determined by absorbance at 260/280 nm using the SpectraMax 190. Reverse transcription was performed by using the GeneAmp Gold RNA PCR core kit (Applied Biosystems, Carlsbad, CA). Total RNA (2 ng) from each sample was reverse transcribed into cDNA in a $40-\mu \mathrm{L}$ reaction [containing $1 \times$ RT-PCR buffer, $2.5 \mathrm{mmol} / \mathrm{L} \mathrm{MgCl} 2,250 \mu \mathrm{mol} / \mathrm{L}$ of each dNTP, $20 \mathrm{U}$ of RNase inhibitor, $10 \mathrm{mmol} / \mathrm{L}$ dithiothreitol, 1.25 $\mu \mathrm{mol} / \mathrm{L}$ random hexamer, and $30 \mathrm{U}$ of MultiScribe Reverse Transcriptase (Qiagen, Valencia, CA)]. Reverse transcription reactions were performed in a thermocycler (PTC-100; MJ Research, Waltham, MA) at $25^{\circ} \mathrm{C}$ for 10 minutes, $42^{\circ} \mathrm{C}$ for 30 minutes, and $95^{\circ} \mathrm{C}$ for 5 minutes.

\section{Quantification of Gene Expression Using Real-Time PCR}

The real-time PCRs were conducted using an ABI prism 7900 sequence detection system and a TaqMan universal PCR master mix kit (Applied Biosystems), as previously described. ${ }^{36}$ Each real-time PCR contained $10 \mu \mathrm{L}$ reverse transcription reaction mix, $25 \mu \mathrm{L} 2 \times$ TaqMan universal PCR master mix, $0.2 \mu \mathrm{mol} / \mathrm{L}$ probe, and $0.6 \mu \mathrm{mol} / \mathrm{L}$ primers. Primer and probe design for the real-time PCR was made with Primer Express version 2 from Applied Biosystems. MLCK-specific primer pairs consisted of 5'-AGGAAGGCAGCATTGAGGTTT-3' (forward) and 5'GCTTTCAGCAGGCAGAGGTAA- $3^{\prime}$ (reverse). The probe specific for MLCK consisted of fluorescein 5'-TGAAGATGCTGGCTCC- $3^{\prime}$ tetramethylrhodamine. The internal control housekeeping gene GAPDH (glyceraldehyde-3phosphate dehydrogenase) specific primer pairs consisted of $5^{\prime}$-CCACCCATGGCAAATTCC-3' (forward) and $5^{\prime}$ TGGGATTTCCATTGATGACCAG-3' (reverse). The probe specific for $G A P D H$ consisted of $4^{\prime}, 5^{\prime}$-dichloro- $2^{\prime}, 7^{\prime}$ dimethoxy-fluorescein $\quad 5^{\prime}$-TGGCACCGTCAAGGCTGAGAACG-3' tetramethylrhodamine. All runs were performed according to the following PCR protocol: $50^{\circ} \mathrm{C}$ for $2 \mathrm{mi}-$ nutes, $95^{\circ} \mathrm{C}$ for 10 minutes, 40 cycles of $95^{\circ} \mathrm{C}$ for 15 seconds, and $60^{\circ} \mathrm{C}$ for 1 minute. For each sample, real-time PCR was performed in triplicate, and the average $C_{T}$ was calculated. A standard curve was generated to convert the $\mathrm{C}_{\mathrm{T}}$ to copy numbers. MLCK mRNA expression was normalized to glyceraldehyde-3-phosphate dehydrogenase mRNA expression. The average copy number of MLCK mRNA expression in control samples was set to 1.0. The relative expression of MLCK mRNA in treated samples was determined as a fold increase compared with control samples.

\section{Determination of Mouse Intestinal TJ Permeability}

The Laboratory Animal Care and Use Committee at the University of New Mexico (Albuquerque, NM) approved all experimental protocols. TLR-4-null (TLR-4 ${ }^{-1-}$ ), MyD88null $\left(\mathrm{MyD}^{-1-}\right.$ ), and wild-type mice (of C57BL/6 background), aged 9 weeks, were obtained from The Jackson Laboratory (Bar Harbor, ME). Generation of $\mathrm{MLCK}^{-1-}$ mice was described previously. ${ }^{41}$ The mice were kept two per cage in a temperature-controlled room at $25^{\circ} \mathrm{C}$ with a 12:12-hour light-dark cycle (lights on at $7 \mathrm{AM}$ ). Intestinal permeability in an in vivo mouse model system was established using a recycling intestinal perfusion method. ${ }^{42}$ LPS $(0.1 \mathrm{mg} / \mathrm{kg})$ was intraperitoneally injected into the mouse daily up to 5 days. Afterward, a 6-cm segment of mouse small intestine was isolated in an anesthetized mouse, cannulated with a small-diameter plastic tube, and continuously perfused with $5 \mathrm{~mL}$ Krebs-phosphate saline buffer for a 2-hour perfusion period. An external recirculating pump (Econo Pump; Bio-Rad Laboratories) was used to recirculate the perfusate at a constant flow rate $(0.75 \mathrm{~mL} /$ minute) . The body temperature of the mouse was maintained at $37^{\circ} \mathrm{C}$ with a temperature-controlled warming blanket. The intestinal permeability was assessed by measuring the flux rate of the paracellular probe, Texas Red-labeled dextran (mol. wt., 10,000 Da). The water absorption was determined by using a nonabsorbable marker, sodium ferrocyanide (catalog number 39660; Alfa Aesar, Ward Hill, MA).

\section{Laser-Capture Microdissection}

Frozen mouse tissue sections were fixed with $75 \%$ ethanol for 30 seconds and hematoxylin stained for 20 seconds. Then, they were dehydrated with $75 \%$ ethanol, 30 seconds; 95\% ethanol, 30 seconds; $100 \%$ ethanol, 30 seconds; and xylene, 5 minutes. After dehydration, sections were air dried for 5 minutes. The Arcturus PixCell II system (Molecular Devices) was used for microdissection. The sections were captured using a 7.5 - $\mu \mathrm{m}$-diameter laser beam, typically at 80 to $100 \mathrm{mV}$ power with a pulse duration of 0.5 to 1.0 milliseconds. On average, approximately 500 shots were taken per cap, and approximately 1000 cells were obtained per cap. Microdissection caps were inserted into $0.5-\mathrm{mL}$ microcentrifuge tubes containing $350 \mu \mathrm{L}$ of lysis buffer, and total RNA was isolated.

\section{Immunostaining of Phospho-MLC}

In Caco-2 Cells

Phosphorylation of MLC was assessed by immunofluorescence antibody labeling. ${ }^{43}$ At the end of the experimental period, filter-grown Caco-2 monolayers were washed twice in cold PBS and were fixed with $2 \%$ paraformaldehyde for 20 minutes. After being permeabilized with $0.1 \%$ Triton X-100 in PBS at room temperature for 20 minutes, Caco-2 monolayers were then incubated in blocking solution composed of bovine serum albumin and normal donkey serum in PBS for 1 hour. Cells were then labeled with primary antibody in blocking solution for 2 hours. After 
being washed with PBS, the cells were incubated in Cy-3-conjugated secondary antibody for 1 hour at room temperature. ProLong Gold antifade reagent (Invitrogen Life Technologies) was used to mount the filters onto the coverslips. Immunolocalizations of phospho-MLC were visualized using a confocal fluorescence microscope (Meta LSM 510; University of New Mexico Imaging Center) equipped with a Hamamatsu digital camera (Hamamatsu Photonics, Hamamatsu, Japan). Images were processed with LSM 510 software (Carl Zeiss, Oberkochen, Germany).

\section{In Mouse Intestinal Tissue}

Phospho-MLC in mouse intestinal tissue was assessed by immunofluorescence antibody labeling. At the end of the experimental period, mouse tissue sections were fixed with $75 \%$ ethanol for 30 seconds. Then, they were dehydrated with $75 \%$ ethanol, 30 seconds; $95 \%$ ethanol, 30 seconds; $100 \%$ ethanol, 30 seconds; and xylene, 5 minutes. After dehydration, sections were air dried for 5 minutes. The sections were washed twice in cold PBS and were fixed with $2 \%$ paraformaldehyde for 20 minutes. After being permeabilized with $0.1 \%$ Triton $\mathrm{X}-100$ in PBS at room temperature for 20 minutes, tissues were then incubated in blocking solution composed of bovine serum albumin and normal donkey serum in PBS for 1 hour. Tissues were then labeled with primary antibodies in blocking solution overnight at $4^{\circ} \mathrm{C}$. After being washed with PBS, the tissues were incubated in fluorescein isothiocyanate and $\mathrm{Cy}$ 3-conjugated secondary antibodies for 1 hour at room temperature. ProLong Gold antifade reagent was used to mount the tissues. Phospho-MLC was visualized using a fluorescence microscope (Meta LSM 510) equipped with a Hamamatsu digital camera. Images were processed with Zen 2 Imaging software (Carl Zeiss).

\section{Statistical Analysis}

Results are expressed as means \pm SEM. Statistical significance of differences between mean values was assessed with $t$-tests for unpaired data (GraphPad Prism software version 5.00 for Windows; GraphPad Software, Inc., San Diego, CA). All reported significance levels represent two-tailed $P$ values. $P \leq 0.05$ was used to indicate statistical significance. All experiments were repeated at least three times to ensure reproducibility.

\section{Results}

LPS-Induced Increase in Caco-2 TJ Permeability Is Mediated by an Increase in MLCK Protein Expression and Kinase Activity

Previous studies from our laboratory indicated that low, physiologically relevant concentrations of LPS (0.3 to 1.0 $\mathrm{ng} / \mathrm{mL}$ ) caused a time-dependent increase in intestinal TJ permeability without causing cell death. ${ }^{2}$ The basolateral compartment exposure of LPS caused an increase in Caco-2 TJ permeability after 3 to 4 days of exposure to LPS. However, the protein kinase or the effector protein target responsible for the LPS effect on intestinal TJ permeability remained unclear. The possible effect of LPS on junctional localization and expression of TJ proteins, including zonula occludens protein 1 , occludin, claudin 1 , claudin 2 , claudin 3 , or claudin 5 , was examined by immunostaining and immunoblot analysis. LPS did not affect junctional localization or expression of TJ proteins (data not shown). Next, we examined the possible involvement of MLCK as protein kinase regulating the LPS effect. First, the LPS effect on MLCK protein expression in filter-grown Caco-2 monolayers was examined. LPS $(0.3 \mathrm{ng} / \mathrm{mL})$ caused a timedependent increase in Caco-2 MLCK protein expression, starting at days 3 to 4 of LPS treatment (Figure 1A). As shown previously, ${ }^{1,2}$ LPS caused a time-dependent increase in Caco-2 TJ permeability (as measured by mucosal-toserosal flux of paracellular marker inulin), starting at days 3 to 4 after LPS exposure (Table 1). The plot of Caco-2 MLCK protein level versus mucosal-to-serosal inulin flux demonstrated a linear correlation between increase in MLCK levels and increase in paracellular permeability, with a relative correlation coefficient of $r=0.91$ (Figure 1B). This finding suggested a cause-and-effect relationship between the increase in MLCK levels and increase in TJ permeability. Second, the LPS effect on Caco-2 MLCK activity was determined by an in vitro kinase assay of Caco2 MLCK. LPS treatment of filter-grown Caco-2 monolayers resulted in a time-dependent increase in Caco-2 MLCK activity (Figure 1C) and an increase in phosphorylated MLC in Caco-2 monolayers (Figure 1D). Next, the effect of pharmacologic MLCK inhibitor ML-7 on LPS-induced increase in inulin flux was determined. ML-7, at a dose previously shown to inhibit Caco-2 MLCK activity $(10 \mu \mathrm{mol} / \mathrm{L}){ }^{35}$ completely inhibited the LPS-induced increase in MLCK activity (Figure 2A), the increase in mucosal-to-serosal flux of inulin, and the decrease in Caco-2 transepithelial electrical resistance (Figure 2, B and C). These findings suggested that the increase in Caco-2 MLCK activity was required for the increase in Caco-2 TJ permeability.

To further validate the requirement of MLCK in LPSinduced increase in Caco-2 TJ permeability, MLCK was selectively knocked down by transfecting filter-grown Caco2 monolayers with MLCK siRNA. The MLCK siRNA transfection caused a near-complete depletion of MLCK protein expression (Figure 2D). Also, the siRNA knockdown of MLCK caused a significant depletion of MLCK mRNA levels, as assessed by real-time PCR (Figure 2E). The siRNA-induced knock-down of MLCK prevented the LPS-induced increase in inulin flux and decrease in Caco-2 transepithelial electrical resistance (Figure 2, F and G), confirming that the increase in MLCK was responsible for the LPS-induced increase in Caco- 2 TJ permeability. 
A

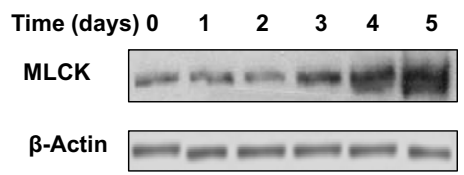

B

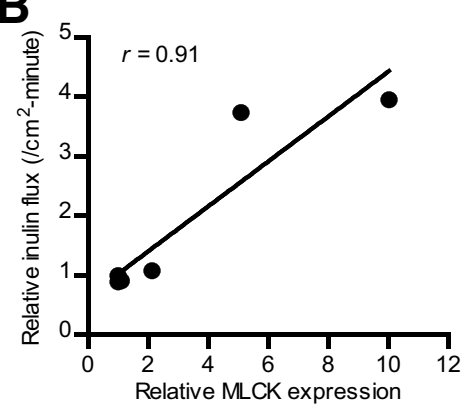

D

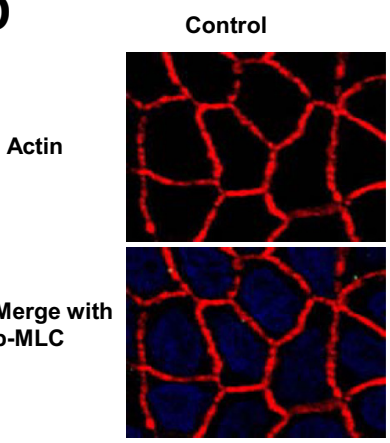

LPS
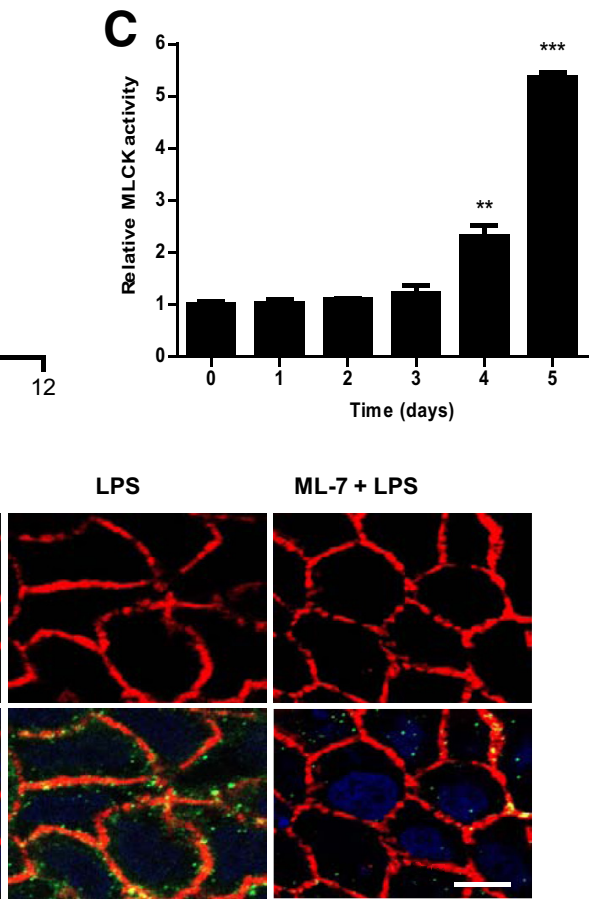

ML-7 + LPS

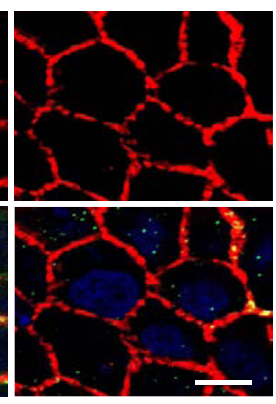

Actin

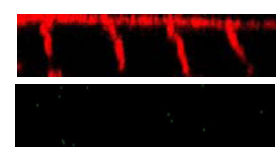

P-MLC

Merge

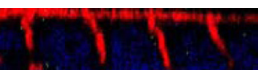

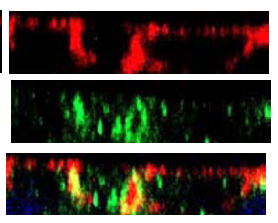

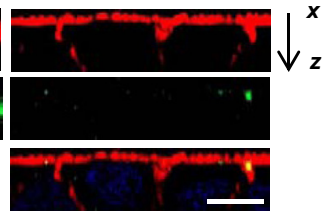

Figure 1 Time-course effect of lipopolysaccharide (LPS) on Caco-2 myosin light chain kinase (MLCK) protein expression, kinase activity, and phosphorylated ( $p$ )-MLC. A: LPS $(0.3 \mathrm{ng} / \mathrm{mL})$ caused a time-dependent increase in MLCK protein expression in Caco-2 monolayers, as determined by Western blot analysis. $\beta$-Actin was used as an internal control for protein loading. Relative densitometry analysis for MLCK protein levels. B: Graph plot of inulin flux versus MLCK protein expression in Caco-2 monolayers (correlation coefficient $r=0.91$ ). C: LPS caused a timedependent increase in MLCK activity, as determined by enzyme-linked immunosorbent assay-based in vitro kinase activity measurement. D: LPS treatment (5-day experimental period) resulted in an increase in $\mathrm{p}-\mathrm{MLC}$ in Caco-2 monolayers, as assayed by immunostaining and visualized by confocal microscopy $(x, 40)$. Control and LPS- and ML-7/LPS-treated cells were stained for actin (red) and P-MLC (green). Minimal changes in actin staining were seen after LPS treatment in $x-y$ plane images (top panels). LPS treatment increased $\mathrm{p}-\mathrm{MLC}$ staining, which colocalized with actin (yellow). In the $x-z$ plane (bottom panels), the actin staining in LPS-treated cells was irregular, with aggregations colocalizing with $\mathrm{P}-\mathrm{MLC}$ (yellow) on the basolateral membrane. Inhibition of MLCK with ML-7 $(10 \mu \mathrm{mol} / \mathrm{L})$ prevented LPS-induced actin rearrangement at the perijunctional sites. Nuclei are stained blue $(x, 40)$. Data are expressed as means \pm SEM (A and C). $n=3$ (A); $n=4$ (C). ${ }^{* * P}<0.01$, ${ }^{* * *} P<0.001$ versus control. Scale bar $=5 \mu \mathrm{m}$ (D).
LPS-Induced Increase in MLCK Expression Is Mediated by TLR-4/MyD88 Signal-Transduction Axis

Previous studies from our laboratory suggested that the LPS-induced increase in intestinal TJ permeability was mediated by the activation of the TLR-4 signal-transduction pathway, involving the TLR-4 receptor complex and the MyD88 signaling axis. ${ }^{1}$ In the following studies, the involvement of the TLR-4 signal-transduction pathway in LPS-induced increase in MLCK expression and activity was examined. The siRNA-induced knock-down of Caco-2 TLR-4 (Figure 3A) prevented the LPS-induced increase in MLCK expression and phosphorylation of MLC (Figure 3, $\mathrm{B}$ and C), suggesting that TLR-4 was required for the LPSinduced increase in Caco-2 MLCK expression and kinase activity. The siRNA-induced knock-down of MyD88
(Figure 3D) also prevented the LPS-induced increase in Caco-2 MLCK expression and MLC phosphorylation (Figure 3, E and F). These findings suggested that the LPSinduced increase in Caco-2 MLCK expression was mediated by the TLR-4/MyD88 signal-transduction pathway.

\section{LPS-Induced Increase in Mouse Intestinal Permeability in Vivo Is Mediated by an Increase in Enterocyte MLCK Expression}

The above studies indicated that MLCK played a key regulatory role in LPS-induced increase in Caco-2 TJ permeability. However, the intracellular processes that mediate the LPS-induced increase in intestinal permeability in live animals remain unknown. In the following 
Table 1 Time-Course Effect of LPS $(0.3 \mathrm{ng} / \mathrm{mL})$ on Mucosal-toSerosal Flux of Paracellular Probe Inulin in Filter-Grown Caco-2 Monolayers

\begin{tabular}{lc}
\hline Time, days & Relative inulin flux, $/ \mathrm{cm}^{2}$-minute \\
\hline 0 & $1.00 \pm 0.021$ \\
1 & $0.9574 \pm 0.0524$ \\
2 & $0.8033 \pm 0.0628$ \\
3 & $4.123 \pm 0.6597$ \\
4 & $5.063 \pm 2.693$ \\
5 & $5.627 \pm 1.752$ \\
\hline
\end{tabular}

$n=6$. Inulin was measured over a 5 -day experimental period of basolateral exposure of Caco-2 monolayers to LPS.

series of studies, the role of MLCK in the LPS-induced increase in mouse intestinal permeability was examined in vivo. In our previous studies, we showed that i.p. LPS $(0.1 \mathrm{mg} / \mathrm{kg}$ body weight) administration causes a timedependent increase in mouse intestinal permeability in vivo. ${ }^{1,2}$ The increase in mouse intestinal permeability was seen between days 3 and 5. The i.p. LPS caused a similar time-dependent increase in intestinal tissue MLCK protein expression (Figure 4A) and mRNA level (Figure 4B) between days 3 and 5. In the control mice, there was only minimal expression of MLCK in the intestinal tissue. LPS treatment caused a marked increase in MLCK expression by day 5. LPS also induced a significant increase in MLCK mRNA level in mouse enterocytes, as determined by real-time PCR assessment of MLCK mRNA in a pure population of mouse enterocytes isolated by laser-capture microdissection (Figure 4C). LPS also caused a marked increase in phosphorylated MLC in mouse enterocytes, as shown in Figure 4D. The time course of intestinal tissue MLCK expression paralleled the increase in mouse intestinal permeability. Interestingly, the in vivo $(0.1 \mathrm{mg} / \mathrm{kg}$ body weight) LPS administration (for 5 days) did not cause an increase in mouse intestinal tissue levels of proinflammatory cytokines, tumor necrosis factor (TNF) $-\alpha$ or IL-1 $\beta$. This finding suggested that the LPS increase in intestinal permeability was not related to an increase in proinflammatory cytokines (Figure 4, E and F). To confirm the requirement of MLCK in LPS-induced increase in intestinal permeability, the effect of LPS on mouse intestinal permeability was examined in MLCK knockout mice. The i.p. LPS did not cause an increase in intestinal permeability in MLCK knockout mice (Figure 5A), indicating that MLCK was required for the increase in mouse intestinal permeability. To further validate the role of MLCK, the effect of MLCK inhibitor, ML7 , on LPS-induced increase in intestinal permeability was also examined. The i.p. ML-7 ( $2 \mathrm{mg} / \mathrm{kg}$ body weight) administration prevented the LPS-induced increase in intestinal permeability (Figure 5B). Together, these data suggested that the LPS-induced increase in MLCK expression was required for the LPS-induced increase in mouse intestinal permeability. The requirement of TLR-4 pathway in LPS effect on mouse intestinal tissue MLCK expression and intestinal permeability was then determined by using TLR-4 and MyD88 knockout mice. In TLR-4 knockout mice, LPS did not cause an increase in mouse intestinal MLCK expression (Figure 5C) or an increase in intestinal permeability (Figure 5D). Similarly, in MyD88 knockout mice, LPS did not cause an increase in mouse MLCK protein and intestinal permeability (Figure 5, E and F). Together, these data suggested that the TLR-4 receptor complex and the MyD88 signaling pathway mediated the LPS-induced increase in enterocyte MLCK and mouse intestinal permeability.

\section{Discussion}

Delineating the cellular and molecular processes that mediate the LPS-induced increase in intestinal epithelial tight junction permeability is important for understanding the cellular mechanisms that lead to intestinal tight junction barrier defects during various inflammatory conditions and for designing potential therapeutic strategies to induce retightening of the intestinal tight junction barrier during inflammatory states. In the present study, we identified the protein kinase responsible for the LPSinduced increase in intestinal TJ permeability. Our results suggested that the LPS-induced increase in intestinal tight junction permeability was not because of an alteration in TJ proteins but because of an increase in expression of MLCK protein. Our data also showed that the LPSinduced increase in MLCK expression and intestinal TJ permeability was mediated by TLR-4/MyD88 signaltransduction pathway up-regulation of the MLCK transcription and translation process. Previous studies from our laboratory had shown that LPS at physiologically relevant concentrations ( 0.3 to $1.0 \mathrm{ng} / \mathrm{mL}$ ) causes a time-dependent increase in intestinal epithelial TJ permeability after 3 to 4 days of exposure. ${ }^{1,2}$ In the present study, our data indicated that the time course of LPS-induced increase in Caco-2 MLCK expression paralleled the increase in Caco-2 MLCK expression. MLCK activity almost perfectly correlated with the increase in Caco-2 TJ permeability, with a correlation coefficient of 0.91. Pharmacologic inhibition of MLCK activity or siRNA knock-down of MLCK completely inhibited the LPS-induced increase in Caco-2 TJ permeability. These findings suggested that the LPS-induced increase in MLCK expression and kinase activity was responsible for the corresponding increase in TJ permeability. As for the intracellular mechanisms that mediate the MLCKdependent increase in TJ permeability, studies from our laboratory and others have shown that the increase in MLCK activity in intestinal epithelial cells produces a catalytic phosphorylation of myosin light chain. ${ }^{35,39,44}$ The phosphorylation of MLC then initiates the activation of $\mathrm{Mg}^{2+}$ actomyosin ATPase and triggers the 

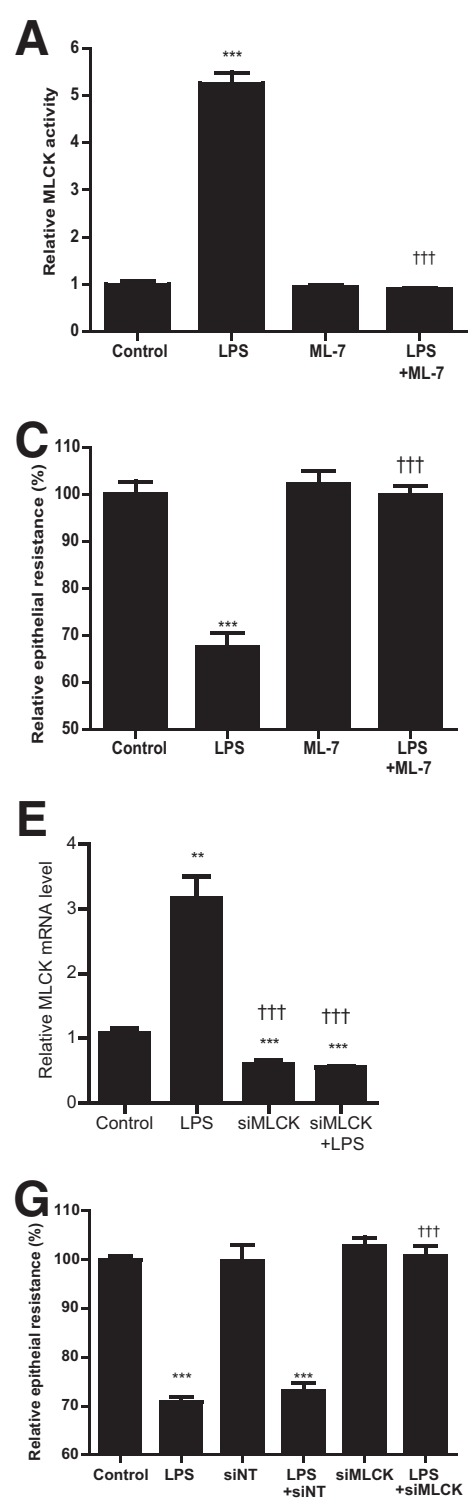

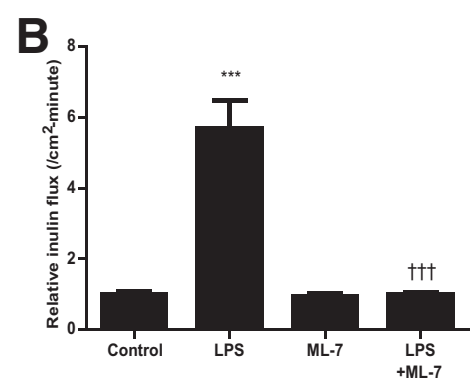

D
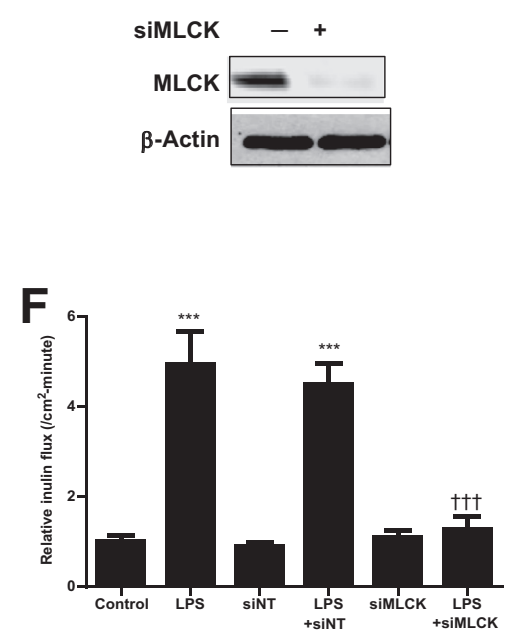

Figure 2 Effect of myosin light chain kinase (MLCK) inhibition on lipopolysaccharide (LPS)-induced increase in Caco-2 MLCK activity and increase in Caco-2 permeability. A: MLCK inhibitor ML-7 $(10 \mu \mathrm{mol} / \mathrm{L})$ significantly prevented the LPS-induced increase in MLCK activity. ML-7 was added 24 hours before LPS treatment, and both LPS and ML-7 were renewed every 24 hours for the 5-day experimental period. B: ML-7 $(10 \mu \mathrm{mol} / \mathrm{L})$ inhibited the LPS-induced increase in inulin flux across Caco-2 monolayers (5-day experimental period). C: ML-7 inhibited the LPS-induced decrease in Caco-2 transepithelial electrical resistance (TER). There was a 5-day experimental period. D: MLCK siRNA transfection resulted in a near complete depletion in MLCK protein expression, as determined by Western blot analysis. siRNA transfection was performed 24 hours before LPS treatment (5-day experimental period). E: MLCK siRNA transfection caused a significant decrease in MLCK mRNA levels, as determined by realtime PCR. siRNA transfection was performed 24 hours before the start of LPS treatment. F: MLCK siRNA transfection prevented the LPS-induced increase in Caco-2 inulin flux. G: MLCK siRNA transfection prevented the LPS-induced decrease in Caco-2 TER. Data are expressed as means \pm SEM (A-C and $\mathbf{E}-\mathbf{G}) . n=4$ (C and $\mathbf{F}) ; n=5$ (E and $\mathbf{G}$ ). ${ }^{* *} P<0.01,{ }^{* * *} P<0.001$ versus control; ${ }^{\dagger \dagger \dagger} P<0.001$ versus LPS treatment. SiMLCK, SiRNA MLCK; siNT, siRNA nontarget. energy-dependent contraction of the perijunctional ring of actin-myosin filaments. This leads to generation of contractile tension and centripetal retraction of perijunctional plasma membrane and TJ complex, culminating in the functional opening of the TJ barrier.

Several studies have shown that LPS at high pharmacologic concentrations (50 to $1000 \mu \mathrm{g} / \mathrm{mL}$ ) causes rapid apoptosis and diffuse cell death in intestinal epithelial cells, leading to massive sloughing of epithelial cells and rapid disintegration of epithelial barrier. ${ }^{8,23,26}$ However, these high concentrations are extreme concentrations, and approximately 10,000 to 100,000 times higher than physiologically achievable concentrations ( 0 to $1.0 \mathrm{ng} / \mathrm{mL}$ ), and do not have physiological or clinical relevance. ${ }^{18,20,45}$ At physiological concentrations ( 0 to $1 \mathrm{ng} / \mathrm{mL}$ ), LPS does not cause epithelial cell death or apoptosis but causes a selective increase in TJ permeability. ${ }^{2}$
It is well established that MLCK plays a central role in the regulation of intestinal epithelial tight junction permeability. ${ }^{3,39}$ It has been shown that, in pharmacologic agent modulation of Caco-2 tight junction permeability by cytochalasin or ethanol, MLCK activation was the intracellular mechanism responsible for the increase in tight junction permeability. ${ }^{46,47}$ These studies demonstrated that there was a rapid increase in specific activity of MLCK kinase activity that was accompanied by contraction of per-junctional actinmyosin filaments and an increase in tight junction permeability. The increase in MLCK activity induced by the pharmacologic agents was because of an increase in the specific activity of the preexisting MLCK and was not associated with an increase in MLCK protein level. In contrast, a proinflammatory cytokine (TNF- $\alpha$ or IL-1 $\beta$ ) induced increase in intestinal TJ permeability was also mediated by an increase in MLCK kinase activity. However, 
A

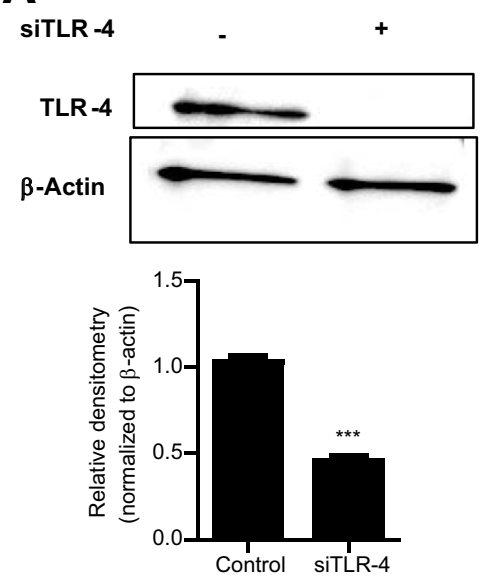

C

P-MLC

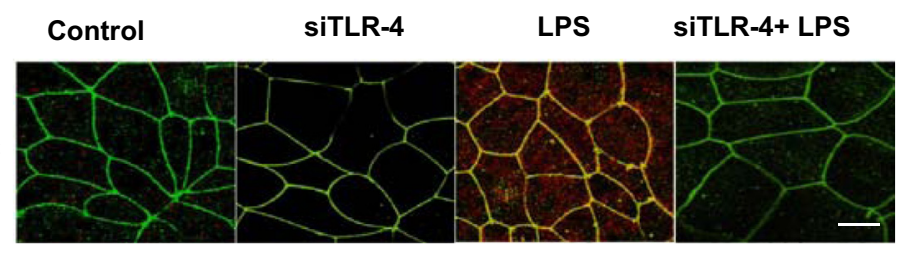

D
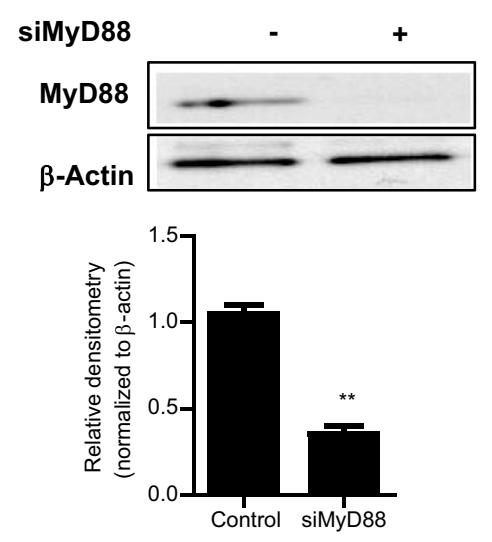

$\mathbf{F}$

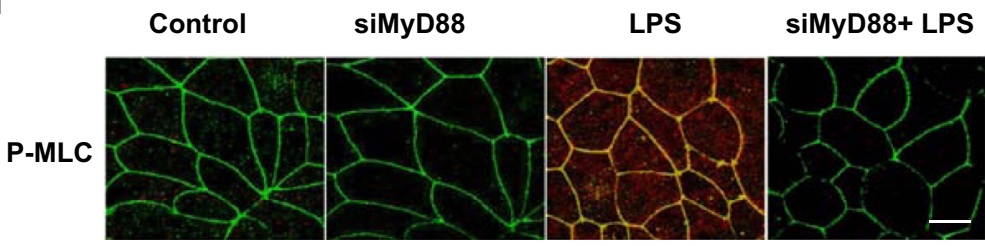

B
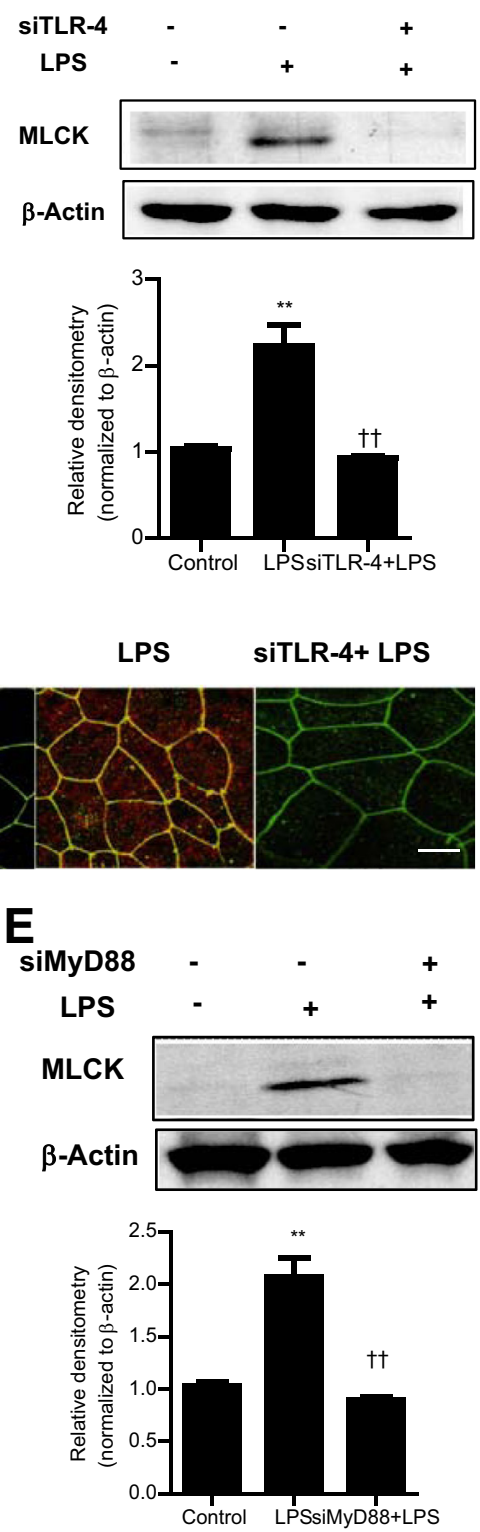

Figure 3 The involvement of the toll-like receptor 4 (TLR-4) signaling pathway in lipopolysaccharide (LPS)-induced activation of myosin light chain kinase (MLCK) in Caco-2 monolayers. A: siRNA-induced knockdown of TLR-4 resulted in a near-complete depletion of TLR-4 expression, as assessed by Western blot analysis. Relative densitometry analysis for TLR-4 protein levels is shown. B: siRNA-induced knock-down of TLR-4 prevented the LPS-induced increase in MLCK protein expression. siRNA transfection was performed 24 hours before LPS treatment (5-day experimental period). C: TLR-4-induced silencing by siRNA prevented the LPSinduced phosphorylation of MLC expression, as assayed by immunostaining and visualized by confocal microscopy (5-day experimental period; $x, 40$ ). D: siRNA-induced knock-down of MyD88 resulted in a near-complete depletion of MyD88 expression, as assessed by Western blot analysis. Relative densitometry analysis for MyD88 protein levels is shown. E: siRNA-induced knock-down of MyD88 prevented the LPS-induced increase in MLCK protein expression. siRNA transfection was performed 24 hours before LPS treatment (5-day experimental period). Relative densitometry analysis for MLCK protein levels is shown. F: MyD88-induced silencing by siRNA prevented the LPS-induced phosphorylation of MLC expression, as assayed by immunostaining and visualized by confocal microscopy $(x, 40)$. Data are expressed as means \pm SEM (A, B, D, and E). $n=3(\mathbf{A}, \mathbf{B}, \mathbf{D}$, and $\mathbf{E}) .{ }^{* *} P<0.01$ versus control; $* * * P<0.001 ;{ }^{\dagger \dagger} P<0.01$ versus LPS treatment. Scale bar $=5 \mu \mathrm{m}$ (C and $\mathbf{F})$. the increase in kinase activity was because of an increase in MLCK protein level and not an increase in specific activity of MLCK. ${ }^{35,39}$

Interestingly, the LPS-induced increase in intestinal epithelial TJ permeability only occurs after 3 to 4 days of LPS exposure. It required an increase in membrane localization of protein components of TLR-4 receptor complex, including both TLR-4 and CD14. ${ }^{1}$ Our results described herein provide a mechanistic explanation for the observed time course of LPS-induced increase in Caco- 2 permeability. The increase in TJ permeability paralleled the increase in MLCK expression and activity. The studies with MLCK gene transcription and pharmacologic inhibitors indicated that the LPS-induced increase in Caco-2 MLCK level was because of an increase in MLCK gene transcription and translation. In this respect, inhibition of MLCK transcription, translation, or enzymatic activity inhibited the LPS-induced increase in Caco-2 TJ permeability. In 
A

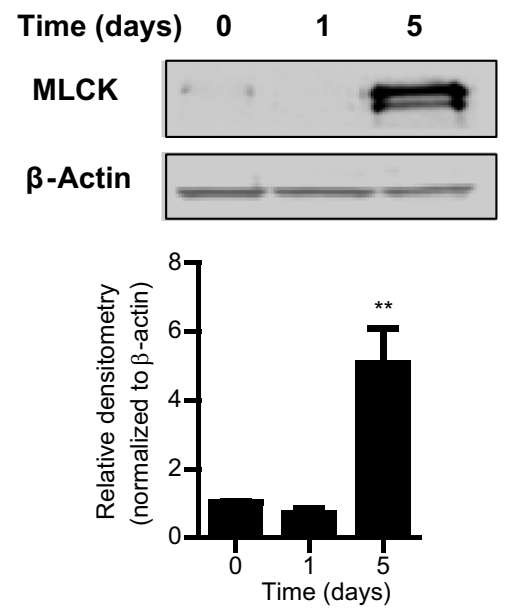

B
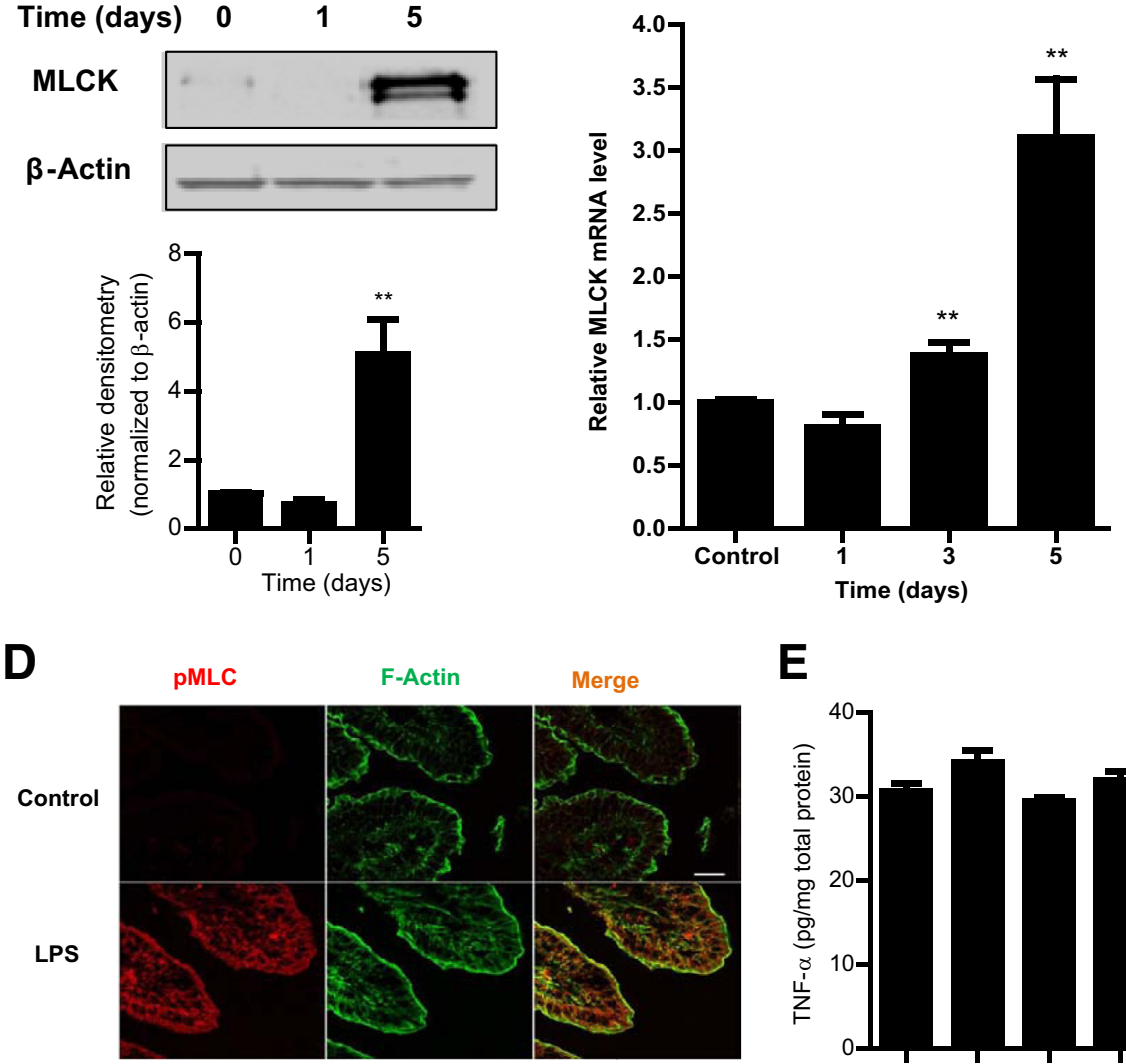

E

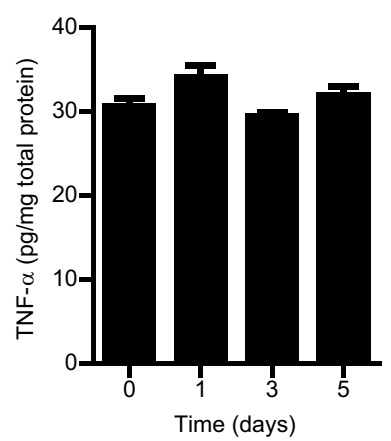

C

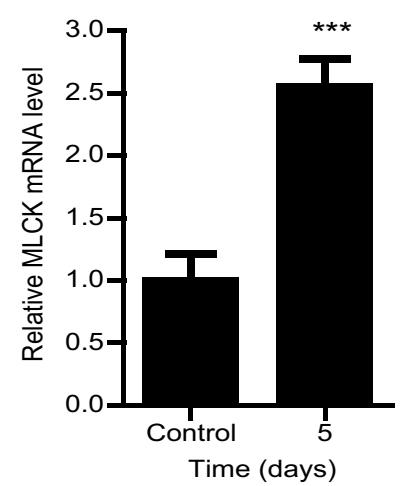

$\mathbf{F}$

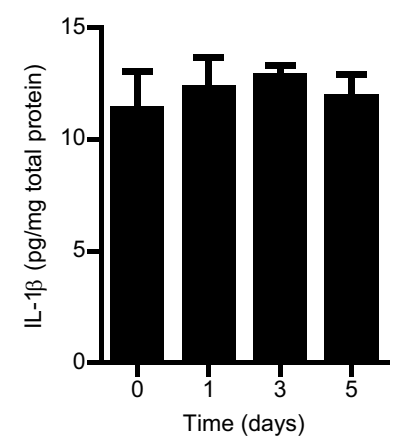

Figure 4 Effect of lipopolysaccharide (LPS) on myosin light chain kinase (MLCK) expression in mouse intestinal tissues in vivo. A: LPS administration (0.1 mg/kg, i.p.) caused a time-dependent increase in MLCK protein expression. Relative densitometry analysis was based on the upper band shown for MLCK expression. B: Increase in mRNA levels, as assessed by real-time PCR. C: LPS caused an increase in mouse MLCK mRNA levels in a pure population of intestinal epithelial cells (ileum) captured by laser-capture microdissection. D: LPS treatment (5-day experimental period) resulted in an increase in phosphorylated (p)-MLC in mouse intestinal tissues (ileum), as assayed by immunostaining and visualized by confocal microscopy $(x, 40)$. E and F: Effect of i.p. LPS ( $0.1 \mathrm{mg} / \mathrm{kg}$ body weight) on mouse intestinal tissue tumor necrosis factor (TNF) $-\alpha$ (E) and IL-1 $\beta$ (F) expression over the 5-day experimental period. LPS treatment did not cause any change in the mouse tissue level of TNF- $\alpha$ or IL-1 $\beta$. Data are expressed as means \pm SEM (A-C, E, and F). $n=4$ (B); $n=5$ (C); $n=3$ (D). ${ }^{* *} P<0.01,{ }^{* * *} P<0.001$ versus control. Scale bar $=5 \mu \mathrm{m}$ (D).

addition, our studies also showed that the LPS-induced increase in MLCK gene transcription and translation was mediated by the TLR-4/MyD88 signal-transduction pathway. In combination with our previous studies, ${ }^{1,2}$ our present findings suggest that LPS binding to the TLR-4 receptor complex activates the MyD88 signaling pathway, which regulates the increase in MLCK mRNA and protein expression.

To determine the potential in vivo relevance of MLCK expression in LPS modulation of intestinal permeability, we also assessed the in vivo effect of LPS on intestinal expression of MLCK and intestinal permeability. As shown previously, the i.p. LPS $(0.1 \mathrm{mg} / \mathrm{kg}$ body weight $)$ administration results in a steady-state serum level of 0.3 to $0.5 \mathrm{ng} / \mathrm{mL}$ in live mouse and a time-dependent increase in mouse intestinal permeability. ${ }^{1,2}$ Our results herein show that LPS also caused an increase in intestinal tissue expression of MLCK by day 5 of LPS exposure. The time course of LPS-induced increase in intestinal tissue MLCK expression correlated with the time course of increase in mouse intestinal permeability; moreover, pharmacologic inhibition of MLCK inhibited the LPS increase in mouse intestinal permeability. LPS also did not cause an increase in intestinal permeability in MLCK knockout mice. Thus, our findings indicated that the LPS induced in mouse intestinal permeability was mediated by an increase in intestinal MLCK expression and activity. In addition, our in vivo studies also indicated that the LPS effect on intestinal tissue MLCK mRNA and protein expression was regulated by the TLR-4/MyD88 signal-transduction pathway. A recent study by Williams et $\mathrm{al}^{48}$ showed that LPS administration at $10 \mathrm{mg} / \mathrm{kg}$ caused rapid intestinal mucosal damage (within 1.5 hours), characterized by massive apoptosis, shedding of epithelial cells, and loss of villus surface (associated with diarrhea) in a mouse model. Interestingly, that study found that the LPS-induced intestinal epithelial cell apoptosis, shedding, and mucosal damage were independent of intestinal epithelial cell 

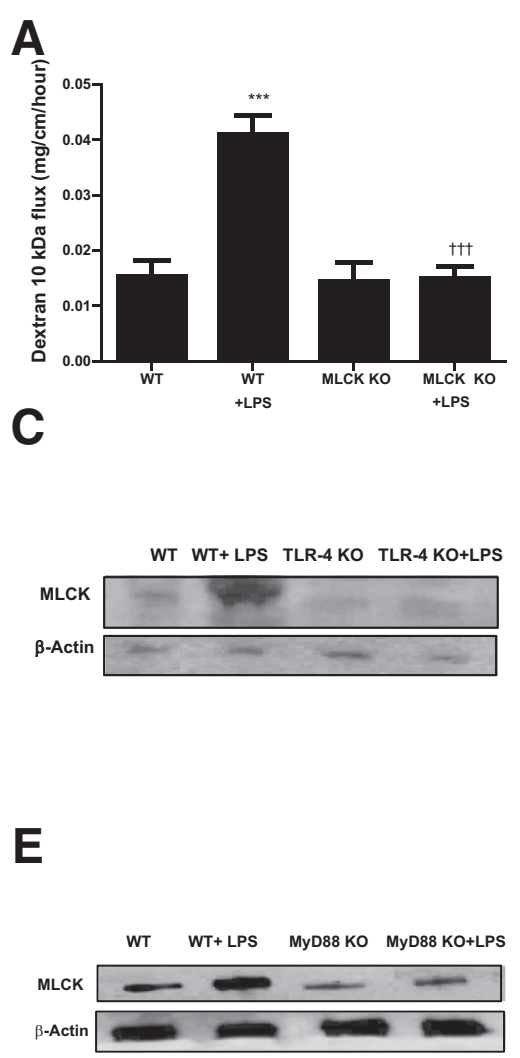

B

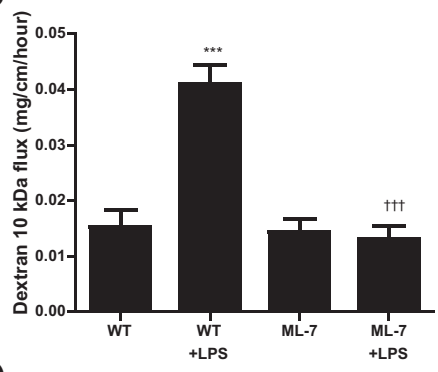

D
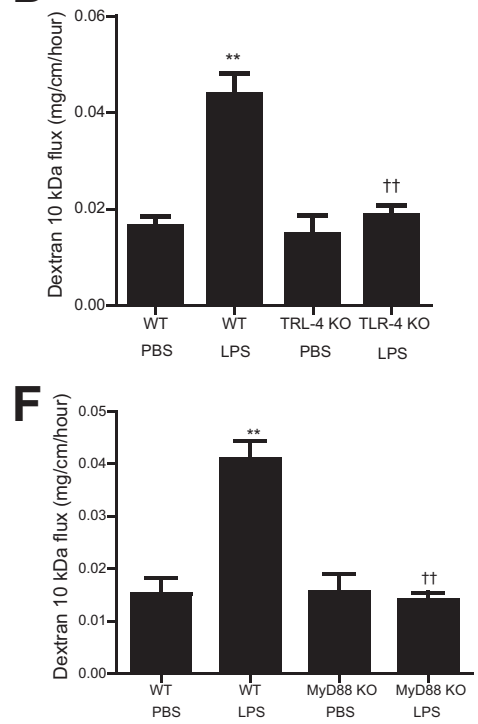

Figure 5 Effect of lipopolysaccharide (LPS) on mouse intestinal permeability in knockout mouse models. A: LPS treatment $(0.1 \mathrm{mg} / \mathrm{kg})$ for a 5 -day experimental period did not induce an increase in mouse intestinal permeability in myosin light chain kinase (MLCK) knockout (KO) mice. B: MLCK inhibitor (ML$7 ; 2 \mathrm{mg} / \mathrm{kg}$ ) significantly prevented the LPS-induced increase in intestinal permeability, as determined by dextran, $10 \mathrm{kDa}$, flux. C: LPS treatment did not affect the MLCK expression in toll-like receptor 4 (TLR-4) KO mice compared with wild-type (WT) mice, as determined by Western blot analysis. D: LPS treatment did not affect the increase in mouse intestinal permeability in TLR-4 KO mice compared with WT mice, as determined by dextran, $10 \mathrm{kDa}$, flux. E: LPS treatment did not affect the MLCK expression in MyD88 KO mice compared with WT mice, as determined by Western blot analysis. F: LPS treatment did not affect the increase in mouse intestinal permeability in MyD88 K0 mice compared with WT mice, as determined by dextran, $10 \mathrm{kDa}$, flux. Data are expressed as means $\pm \operatorname{SEM}(\mathbf{A}, \mathbf{B}, \mathbf{D}$, and $\mathbf{F}) . n=4$ (A and B). ${ }^{* *} P<0.01,{ }^{* *} P<0.001$ versus control WT; ${ }^{\dagger \dagger} P<0.01,{ }^{\dagger \dagger} P<0.001$ versus LPS treatment WT. PBS, phosphate-buffered saline.
MyD88 expression and dependent on epithelial cell TNFreceptor 1 expression. The study concluded that the LPS $(10 \mathrm{mg} / \mathrm{kg}$ ) induced increase in intestinal epithelial cell apoptosis and shedding in mice was independent of the intestinal epithelial cell TLR-4 signal-transduction pathway. Instead, it was attributable to an increase in TNF$\alpha$-induced intestinal epithelial cell apoptosis. In contrast, our results in this study showed that the in vivo $(0.1 \mathrm{mg} / \mathrm{kg}$ body weight) LPS administration (for 5 days) did not cause an increase in mouse intestinal tissue levels of proinflammatory cytokines, TNF- $\alpha$ or IL-1 $\beta$. These findings suggested that the LPS increase in intestinal permeability was not related to an increase in proinflammatory cytokines (Figure 4, E and F), and was dependent on the TLR4/MyD88 signal-transduction pathway.

The importance of MLCK in the in vivo regulation of intestinal permeability has been well demonstrated. Moriez et $\mathrm{al}^{49}$ showed that treatment with a high dose of LPS at $1 \mathrm{mg} / \mathrm{kg}$ in rats caused a transient increase in colonic paracellular permeability ( 0 to 6 hours), an increase in bacterial translocation, mucosal damage, and an increase in MLC phosphorylation in colonic tissues. However, this study has not demonstrated the effect of a physiologically relevant concentration of LPS on MLCK gene and protein expression. The number of studies has demonstrated that, in animal models of intestinal inflammation, the increase in intestinal permeability was associated with an increase in intestinal MLCK expression. Inhibition of MLCK expression or MLCK activity inhibited the increase in intestinal permeability and subsequent development of intestinal inflammation. ${ }^{50-52}$ In both mouse models of dextran sulfate sodium-induced colitis and T-cell transferinduced colitis, alteration in intestinal permeability preceded the development of intestinal inflammation; inhibitors of MLCK activity prevented the increase in intestinal permeability and intestinal inflammation. ${ }^{51,53,54}$ Similarly, patients with Crohn disease and ulcerative colitis have a marked increase in MLCK expression, which also correlated with the disease activity. ${ }^{55}$ In this regard, MLCK inhibitors are being targeted as a possible therapy for inflammatory bowel disease.

In conclusion, our data show that MLCK is a protein kinase that mediates the LPS-induced increase in intestinal epithelial tight junction permeability. The physiologically and clinically relevant concentrations of LPS-induced increase in intestinal epithelial TJ permeability (in vitro and in vivo) were regulated by a distinct intracellular signaling process in which MLCK gene and protein expression and kinase activity are regulated by the TLR-4/MyD88 signaltransduction pathway. Thus, our present data provide important new insight into the intracellular mechanisms and effector protein that mediate LPS-induced increase in intestinal epithelial tight junction permeability in vitro and in vivo. 


\section{References}

1. Guo S, Nighot M, Al-Sadi R, Alhmoud T, Nighot P, Ma TY: Lipopolysaccharide regulation of intestinal tight junction permeability is mediated by TLR4 signal transduction pathway activation of FAK and MyD88. J Immunol 2015, 195:4999-5010

2. Guo S, Al-Sadi R, Said HM, Ma TY: Lipopolysaccharide causes an increase in intestinal tight junction permeability in vitro and in vivo by inducing enterocyte membrane expression and localization of TLR-4 and CD14. Am J Pathol 2013, 182:375-387

3. Zareie M, Singh PK, Irvine EJ, Sherman PM, McKay DM, Perdue MH: Monocyte/macrophage activation by normal bacteria and bacterial products: implications for altered epithelial function in Crohn's disease. Am J Pathol 2001, 158:1101-1109

4. Caradonna L, Amati L, Magrone T, Pellegrino NM, Jirillo E, Caccavo D: Enteric bacteria, lipopolysaccharides and related cytokines in inflammatory bowel disease: biological and clinical significance. J Endotoxin Res 2000, 6:205-214

5. Scaldaferri F, Lopetuso LR, Petito V, Cufino V, Bilotta M, Arena V, Stigliano E, Maulucci G, Papi M, Emiliana CM, Poscia A, Franceschi F, Delogu G, Sanguinetti M, Spirito MD, Sgambato A, Gasbarrini A: Gelatin tannate ameliorates acute colitis in mice by reinforcing mucus layer and modulating gut microbiota composition: emerging role for "gut barrier protectors" in IBD? United European Gastroenterol J 2014, 2:113-122

6. Zhao H, Zhang H, Wu H, Li H, Liu L, Guo J, Li C, Shih DQ, Zhang X: Protective role of 1,25(OH)2 vitamin D3 in the mucosal injury and epithelial barrier disruption in DSS-induced acute colitis in mice. BMC Gastroenterol 2012, 12:57

7. Yousef M, Pichyangkura R, Soodvilai S, Chatsudthipong V, Muanprasat C: Chitosan oligosaccharide as potential therapy of inflammatory bowel disease: therapeutic efficacy and possible mechanisms of action. Pharmacol Res 2012, 66:66-79

8. Yu LC, Flynn AN, Turner JR, Buret AG: SGLT-1-mediated glucose uptake protects intestinal epithelial cells against LPS-induced apoptosis and barrier defects: a novel cellular rescue mechanism? FASEB J 2005, 19:1822-1835

9. Tomita M, Ohkubo R, Hayashi M: Lipopolysaccharide transport system across colonic epithelial cells in normal and infective rat. Drug Metab Pharmacokinet 2004, 19:33-40

10. Schroder NW, Heine H, Alexander C, Manukyan M, Eckert J, Hamann L, Gobel UB, Schumann RR: Lipopolysaccharide binding protein binds to triacylated and diacylated lipopeptides and mediates innate immune responses. J Immunol 2004, 173:2683-2691

11. Luscinskas FW, Leick M, Newton G, Nusrat A: Introduction for the special issue on "Tissue Barriers in Inflammation." Tissue Barriers 2015, 3:e1015825

12. Chen SW, Wang PY, Zhu J, Chen GW, Zhang JL, Chen ZY, Zuo S, Liu YC, Pan YS: Protective effect of 1,25-dihydroxyvitamin d3 on lipopolysaccharide-induced intestinal epithelial tight junction injury in caco-2 cell monolayers. Inflammation 2015, 38:375-383

13. Chatterton DE, Nguyen DN, Bering SB, Sangild PT: Anti-inflammatory mechanisms of bioactive milk proteins in the intestine of newborns. Int J Biochem Cell Biol 2013, 45:1730-1747

14. Wolfs TG, Derikx JP, Hodin CM, Vanderlocht J, Driessen A, de Bruine AP, Bevins CL, Lasitschka F, Gassler N, van Gemert WG, Buurman WA: Localization of the lipopolysaccharide recognition complex in the human healthy and inflamed premature and adult gut. Inflamm Bowel Dis 2010, 16:68-75

15. Uesugi T, Froh M, Arteel GE, Bradford BU, Wheeler MD, Gabele E, Isayama F, Thurman RG: Role of lipopolysaccharide-binding protein in early alcohol-induced liver injury in mice. J Immunol 2002, 168:2963-2969

16. Schafer C, Parlesak A, Schutt C, Bode JC, Bode C: Concentrations of lipopolysaccharide-binding protein, bactericidal/permeability-increasing protein, soluble CD14 and plasma lipids in relation to endotoxaemia in patients with alcoholic liver disease. Alcohol Alcohol 2002, 37:81-86
17. Mandrekar P, Szabo G: Signalling pathways in alcohol-induced liver inflammation. J Hepatol 2009, 50:1258-1266

18. Andreasen AS, Krabbe KS, Krogh-Madsen R, Taudorf S, Pedersen BK, Moller K: Human endotoxemia as a model of systemic inflammation. Curr Med Chem 2008, 15:1697-1705

19. Hurley JC: Endotoxemia: methods of detection and clinical correlates Clin Microbiol Rev 1995, 8:268-292

20. Sharma R, Tepas JJ 3rd, Hudak ML, Mollitt DL, Wludyka PS, Teng RJ, Premachandra BR: Neonatal gut barrier and multiple organ failure: role of endotoxin and proinflammatory cytokines in sepsis and necrotizing enterocolitis. J Pediatr Surg 2007, 42:454-461

21. Liu HY, Li WQ, Wang XY, Li JS, Yu WK: Early gut mucosal dysfunction in patients with acute pancreatitis. Pancreas 2008, 36:192-196

22. Marshall JC, Walker PM, Foster DM, Harris D, Ribeiro M, Paice J, Romaschin AD, Derzko AN: Measurement of endotoxin activity in critically ill patients using whole blood neutrophil dependent chemiluminescence. Crit Care 2002, 6:342-348

23. Forsythe RM, Xu DZ, Lu Q, Deitch EA: Lipopolysaccharide-induced enterocyte-derived nitric oxide induces intestinal monolayer permeability in an autocrine fashion. Shock 2002, 17:180-184

24. Hirotani Y, Ikeda K, Kato R, Myotoku M, Umeda T, Ijiri Y, Tanaka K: Protective effects of lactoferrin against intestinal mucosal damage induced by lipopolysaccharide in human intestinal Caco-2 cells. Yakugaku Zasshi 2008, 128:1363-1368

25. Kim ID, Ha BJ: Paeoniflorin protects RAW 264.7 macrophages from LPS-induced cytotoxicity and genotoxicity. Toxicol In Vitro 2009, 23:1014-1019

26. Liu C, Li A, Weng YB, Duan ML, Wang BE, Zhang SW: Changes in intestinal mucosal immune barrier in rats with endotoxemia. World J Gastroenterol 2009, 15:5843-5850

27. Yu Y, Liu ZQ, Liu XY, Yang L, Geng XR, Yang G, Liu ZG, Zheng PY, Yang PC: Stress-derived corticotropin releasing factor breaches epithelial endotoxin tolerance. PLoS One 2013, 8:e65760

28. Vogel SN, Marshall ST, Rosenstreich DL: Analysis of the effects of lipopolysaccharide on macrophages: differential phagocytic responses of C3H-HeN and C3H-HeJ macrophages in vitro. Infect Immun 1979, 25:328-336

29. Ohlmann P, Tesse A, Loichot C, Ralay Ranaivo H, Roul G, Philippe C, Watterson DM, Haiech J, Andriantsitohaina R: Deletion of MLCK210 induces subtle changes in vascular reactivity but does not affect cardiac function. Am J Physiol Heart Circ Physiol 2005, 289:H2342-H2349

30. Verin AD, Lazar V, Torry RJ, Labarrere CA, Patterson CE, Garcia JG: Expression of a novel high molecular-weight myosin light chain kinase in endothelium. Am J Respir Cell Mol Biol 1998, 19: $758-766$

31. Lazar V, Garcia JG: A single human myosin light chain kinase gene (MLCK; MYLK). Genomics 1999, 57:256-267

32. Garcia JG, Lazar V, Gilbert-McClain LI, Gallagher PJ, Verin AD: Myosin light chain kinase in endothelium: molecular cloning and regulation. Am J Respir Cell Mol Biol 1997, 16:489-494

33. Clayburgh DR, Rosen S, Witkowski ED, Wang F, Blair S, Dudek S, Garcia JG, Alverdy JC, Turner JR: A differentiation-dependent splice variant of myosin light chain kinase, MLCK1, regulates epithelial tight junction permeability. J Biol Chem 2004, 279:55506-55513

34. Al-Sadi R, Boivin M, Ma T: Mechanism of cytokine modulation of epithelial tight junction barrier. Front Biosci (Landmark Ed) 2009, 14: $2765-2778$

35. Al-Sadi R, Ye D, Dokladny K, Ma TY: Mechanism of IL-1betainduced increase in intestinal epithelial tight junction permeability J Immunol 2008, 180:5653-5661

36. Ma TY, Iwamoto GK, Hoa NT, Akotia V, Pedram A, Boivin MA, Said HM: TNF-alpha-induced increase in intestinal epithelial tight junction permeability requires NF-kappa B activation. Am J Physiol Gastrointest Liver Physiol 2004, 286:G367-G376

37. Johnston DG, Corr SC: Toll-like receptor signalling and the control of intestinal barrier function. Methods Mol Biol 2016, 1390:287-300 
38. Chang JX, Chen S, Ma LP, Jiang LY, Chen JW, Chang RM, Wen LQ, Wu W, Jiang ZP, Huang ZT: Functional and morphological changes of the gut barrier during the restitution process after hemorrhagic shock. World J Gastroenterol 2005, 11:5485-5491

39. Ye D, Ma I, Ma TY: Molecular mechanism of tumor necrosis factoralpha modulation of intestinal epithelial tight junction barrier. Am J Physiol Gastrointest Liver Physiol 2006, 290:G496-G504

40. Al-Sadi RM, Ma TY: IL-1beta causes an increase in intestinal epithelial tight junction permeability. J Immunol 2007, 178: 4641-4649

41. Wainwright MS, Rossi J, Schavocky J, Crawford S, Steinhorn D, Velentza AV, Zasadzki M, Shirinsky V, Jia YZ, Haiech J, Van Eldik LJ, Watterson DM: Protein kinase involved in lung injury susceptibility: evidence from enzyme isoform genetic knockout and in vivo inhibitor treatment. Proc Natl Acad Sci U S A 2003, 100: $6233-6238$

42. Clayburgh DR, Barrett TA, Tang Y, Meddings JB, Van Eldik LJ, Watterson DM, Clarke LL, Mrsny RJ, Turner JR: Epithelial myosin light chain kinase-dependent barrier dysfunction mediates $\mathrm{T}$ cell activation-induced diarrhea in vivo. J Clin Invest 2005, 115: $2702-2715$

43. Madara JL, Barenberg D, Carlson S: Effects of cytochalasin D on occluding junctions of intestinal absorptive cells: further evidence that the cytoskeleton may influence paracellular permeability and junctional charge selectivity. J Cell Biol 1986, 102:2125-2136

44. Weber CR, Raleigh DR, Su L, Shen L, Sullivan EA, Wang Y, Turner JR: Epithelial myosin light chain kinase activation induces mucosal interleukin-13 expression to alter tight junction ion selectivity. J Biol Chem 2016, 285:12037-12046

45. Wellmann W, Fink PC, Benner F, Schmidt FW: Endotoxaemia in active Crohn's disease: treatment with whole gut irrigation and 5aminosalicylic acid. Gut 1986, 27:814-820

46. Ma TY, Nguyen D, Bui V, Nguyen H, Hoa N: Ethanol modulation of intestinal epithelial tight junction barrier. Am J Physiol 1999, 276: G965-G974

47. Ma TY, Hoa NT, Tran DD, Bui V, Pedram A, Mills S, Merryfield M: Cytochalasin B modulation of Caco-2 tight junction barrier: role of myosin light chain kinase. Am J Physiol Gastrointest Liver Physiol 2000, 279:G875-G885
48. Williams JM, Duckworth CA, Watson AJM, Frey MR, Miguel JC, Burkitt MD, Sutton R, Hughes KR, Hall LJ, Caamano JH, Campbelll BJ, Pritchard DM: A mouse model of pathological small intestinal epithelial cell apoptosis and shedding induced by systemic administration of lipopolysaccharide. Dis Model Mech 2013, 6: $1388-1399$

49. Moriez R, Salvador-Cartier C, Theodorou V, Fioramonti J, Eutamene H, Bueno L: Myosin light chain kinase is involved in lipopolysaccharide-induced disruption of colonic epithelial barrier and bacterial translocation in rats. Am J Pathol 2005, 167: $1071-1079$

50. Costantini TW, Loomis WH, Putnam JG, Kroll L, Eliceiri BP, Baird A, Bansal V, Coimbra R: Pentoxifylline modulates intestinal tight junction signaling after burn injury: effects on myosin light chain kinase. J Trauma 2009, 66:17-24. discussion 24-25

51. Feighery LM, Cochrane SW, Quinn T, Baird AW, O'Toole D, Owens SE, O’Donoghue D, Mrsny RJ, Brayden DJ: Myosin light chain kinase inhibition: correction of increased intestinal epithelial permeability in vitro. Pharm Res 2008, 25:1377-1386

52. Clayburgh DR, Musch MW, Leitges M, Fu YX, Turner JR: Coordinated epithelial NHE3 inhibition and barrier dysfunction are required for TNF-mediated diarrhea in vivo. J Clin Invest 2006, 116 : 2682-2694

53. Nighot P, Al-Sadi R, Rawat M, Guo S, Watterson DM, Ma T: Matrix metalloproteinase 9-induced increase in intestinal epithelial tight junction permeability contributes to the severity of experimental DSS colitis. Am J Physiol Gastrointest Liver Physiol 2015, 309: G988-G997

54. Su L, Nalle SC, Shen L, Turner ES, Singh G, Breskin LA, Khramtsova EA, Khramtsova G, Tsai PY, Fu YX, Abraham C, Turner JR: TNFR2 activates MLCK-dependent tight junction dysregulation to cause apoptosis-mediated barrier loss and experimental colitis. Gastroenterology 2013, 145: $407-415$

55. Lapointe TK, Buret AG: Interleukin-18 facilitates neutrophil transmigration via myosin light chain kinase-dependent disruption of occludin, without altering epithelial permeability. Am J Physiol Gastrointest Liver Physiol 2012, 302: G343-G351 